\section{Análisis sobre los modos digitales de difusión de las grandes editoriales en Argentina: libros de "coyuntura política" en las redes sociales}

Ana Slimovich ${ }^{\star}$ y Ezequiel Saferstein ${ }^{\star *}$

\begin{abstract}
Resumen: Entre los desafíos que enfrentan las editoriales universitarias para intervenir y competir en un mercado editorial concentrado, se encuentra tanto el armado de un catálogo que conjugue temas y perspectivas atractivos para un público amplio, como la actualización en las herramientas de digitalización para la difusión de sus productos impresos. Las redes sociales -y sus lógicas- se constituyeron en espacios clave para la difusión de libros. El trabajo se propone analizar la emergencia y recepción de libros de coyuntura política publicados en 2018, teniendo en cuenta los modos de mediatización en las redes sociales, tomando como caso al grupo Planeta, uno de los principales actores del sector.
\end{abstract}

Palabras clave: Editorial - Libros - Redes sociales - Discurso - Mediatización.

[Resúmenes en inglés y portugués en la página 188]

${ }^{(*)}$ Doctora en Ciencias Sociales y licenciada en Ciencias de la Comunicación (UBA). Becaria posdoctoral del CONICET, Instituto de Investigaciones Gino Germani (UBA). Se desempeña como docente en "Semiótica de redes", cátedra Mario Carlón, en la carrera de Ciencias de la Comunicación (UBA). Forma parte del proyecto de investigación UBACyT: "La mediatización en el entretejido de los vínculos sociales". Es profesora visitante de "Semiótica" en la carrera de Comunicación (Universidad de San Andrés -UdeSA-). aslimovich@gmail.com

${ }^{(*)}$ Sociólogo (UBA), especializado en sociología de la cultura y análisis cultural (IDAESUNSAM). Doctor en Ciencias Sociales (UBA). Investigador asistente (CeDInCI/UNSAM - CONICET). Docente de la UBA. Participa en grupos de investigación y proyectos financiados vinculados al estudio del campo editorial, sobre la producción cultural en general y sobre las transformaciones vinculadas a la esfera cultural. kielo84@gmail.com

\title{
Introducción
}

En los últimos años el mercado editorial registró un aumento en la producción de libros de "coyuntura política", segmento que comprende a una serie de títulos de no ficción que 
abordan temas de actualidad política y el pasado reciente desde la óptica del ensayo o de la investigación periodística. Escritos por periodistas, intelectuales, escritores e incluso políticos, tienen una amplia visibilidad en el circuito de comunicación conformado también por los medios masivos de comunicación como la prensa, la radio y la televisión, así como por las redes sociales (Saferstein, 2016).

Este segmento se constituyó como uno de los más importantes en términos de producción, circulación y consumo, cuestión que se evidencia en los rankings de venta de las librerías, en la presencia de reseñas, en las entrevistas a sus autores y en las notas en los medios, así como en la utilización de algunos de los libros como insumo y pruebas en causas judiciales (Hernández y Saferstein, 2018). En este sentido, estos libros tienen una relevancia central para las empresas editoriales, que producen y hacen circular libros que impactan en importantes retornos económicos en un tiempo acotado.

Como una cuestión que atraviesa esta producción, el proceso de mediatización se ha acelerado en las últimas décadas y ha sufrido una nueva transformación con la llegada de los nuevos medios, la crisis de los medios masivos (Carlón y Scolari, 2009, Verón, 2011 [2007]) y con la entrada en una sociedad hipermediatizada (Carlón, 2015). Una editorial puede difundir la salida al mercado de un libro desde una publicación en una red social y luego producirse un "salto de escala en el proceso de la mediatización" (Carlón, 2016) y alcanzar también ese discurso los medios masivos de comunicación. Los modos de producir discursos por parte de los actores políticos en las redes sociales impactan en el "espacio público ensanchado" y suponen procesos de interfaz con las lógicas, reglas y contenidos de lo informativo/periodístico, así como espacios de desintermediación en los cuales los políticos se vinculan por primera vez con los ciudadanos sin intermediarios periodistas (Slimovich, 2012). Los modos digitales de promoción conviven con las estrategias de difusión tradicional en la prensa gráfica, televisión y vía pública. Es por ello que un análisis sobre los modos digitales de difusión resulta relevante para observar cómo las editoriales llevan adelante el proceso de promoción de estos productos a través de estos soportes/ medios/redes sociales y cómo son recibidos por los consumidores de sus redes y de sus libros de "coyuntura política".

Construir un catálogo que conjugue temas y perspectivas atractivas para un público amplio (lo que implica, en gran medida, cierta articulación con la coyuntura), así como la actualización constante en las herramientas de digitalización para la difusión de los productos impresos se constituyeron en los últimos años como desafíos indispensables para el espacio editorial. Para intervenir y competir en un mercado editorial concentrado, las editoriales universitarias no pueden ser ajenas a estos desafíos. Siendo la producción académica su principal activo, el cual no es detentado por las grandes editoriales que se exploran en este trabajo, pueden valerse de las estrategias que estos grupos emplean, favorecidos por un mercado que controlan en gran medida. En el marco del presente dossier dedicado a la edición universitaria, el artículo busca dar cuenta de procesos actuales del espacio editorial que interpelan a todas las empresas, pero que hegemonizan los grandes grupos. El siguiente trabajo se propone analizar la emergencia y recepción de libros de "coyuntura política" publicados durante el 2018 en Argentina, teniendo en cuenta los modos de vehiculizar los discursos de las editoriales contemporáneas en las redes sociales. Se tendrá en cuenta la vía de difusión de las obras en las cuentas de Facebook, Twitter e Instagram en las 
grandes editoriales, centrándose en el grupo Planeta y sus sellos, los modos de difusión de los propios políticos, así como los modos de respuesta de los internautas. La investigación se concentrará en el análisis de la aparición de discursos ligados a la salida de un libro al mercado en las redes sociales, así como a los modos de exhibición de la presentación pública del libro en las distintas ciudades del país.

Teniendo en cuenta que los discursos vehiculizan sentidos, imaginarios y representaciones, y que sus efectos también están vinculados al soporte, medio o red social bajo el cual emergen, se realizará un análisis que contemple los modos de materialización de esos discursos, las diferencias por la red social, así como entre las distintas editoriales, que varían según tamaño, estructura y posición en el campo editorial según su capital simbólico acumulado.

El trabajo aborda los siguientes interrogantes: ¿qué lugar ocupan las redes sociales en el proceso de difusión de las editoriales de las obras de autores que pertenecen al mundo de la política? ¿Qué características poseen los discursos de las editoriales en Facebook, Twitter, Instagram? ¿Qué continuidades y rupturas aparecen entre la promoción por parte de las editoriales y la que realizan los propios autores en sus redes? ¿Cómo circulan las discursividades ligadas a la presentación de un libro de coyuntura política en las redes sociales? ¿Cómo son recibidas por los internautas?

Para contestar estas preguntas, el trabajo se articula de la siguiente forma. En primer lugar, se presenta la metodología utilizada y el corpus construido. En segundo lugar, se detallan los fundamentos teóricos de esta investigación, teniendo en cuenta los modos de producir libros de "coyuntura política" por parte de los conglomerados editoriales, así como los modos históricos de mediatización de la política contemporánea. En tercer lugar, se presenta el análisis socio-semiótico de los modos de emergencia de los discursos del grupo Planeta en las redes, de los autores y las respuestas por parte de los internautas. Por último, se esbozan las consideraciones finales.

\section{Metodología}

Este trabajo combina y articula distintas técnicas de recolección de datos y de análisis. Por un lado, un conjunto de datos cualitativos surge de un proyecto de investigación más amplio centrado en el análisis del espacio editorial argentino a partir de las prácticas y representaciones de los editores, autores, agentes de marketing y prensa de grandes, medianas y pequeñas editoriales ${ }^{1}$. En el marco de ese proyecto, se realizaron 40 entrevistas en profundidad, semiestructuradas, con cuestionarios abiertos, que exploran la labor editorial, las trayectorias profesionales, los modos de producción, circulación y difusión de libros y el uso de las redes sociales por parte de las editoriales. Las entrevistas fueron realizadas a agentes que participan en editoriales que publican libros de "coyuntura política" y se complementan con observaciones en contexto y observaciones en ferias y presentaciones. Además, se utilizan indicadores de actividad en el sector a partir de fuentes secundarias y de bases de datos propias sobre temas vinculados a la actividad editorial (Saferstein, 2016). Por otro lado, se conjuga el tradicional análisis de la semiótica de medios masivos -es decir, el estudio de lo retórico, lo temático y lo enunciativo, los géneros, dispositivos y 
medios- con el herramental metodológico de análisis de la circulación hipermediática contemporánea (Carlón, 2015, 2016; Carlón, Fraticelli, Slimovich y Rovner, 2017)². Por último, en otra investigación se ha realizado un análisis de los modos de mediatización de la política argentina contemporánea en las redes sociales y las operaciones productoras de sentido implicadas en las discursividades digitales de los políticos argentinos entre 2011 y 2018 (Slimovich, 2012, 2016, 2017, 2018). Para este trabajo se realizará una indagación de tipo comparativa que permitirá determinar las características de los discursos de difusión de libros de "coyuntura política" por parte de las editoriales en Facebook, Twitter e Instagram.

El dispositivo analítico de la circulación hipermediática de los discursos sociales contemporáneos (Carlón, 2015), siguiendo el modelo de análisis de Verón (1987a), conceptualiza la mediatización contemporánea en cuatro figuras y sus relaciones: instituciones, medios, colectivos e individuos. Por esta razón, en el siguiente trabajo se describirán los modos de emergencia de los colectivos de internautas en relación con la salida al mercado de los libros de coyuntura, qué tipo de relación constituyeron con la institución editorial, con los medios masivos y periodistas, así como con el autor. El corpus está conformado por dos libros argentinos que salieron al mercado en el segundo semestre de 2018. En primer lugar, Peronismo, Pampa y Peligro: Mi vida en la política argentina de Felipe Solá, editado por Ariel (Grupo Planeta). En segundo lugar, Big Macri. Del cambio al FMI, de Gabriela Cerruti, también editado por Planeta.

\section{La industria editorial argentina y el fenómeno reciente de los libros de coyuntura política}

En la Argentina de los últimos años, se registró un crecimiento en la producción, circulación y consumo de libros publicados principalmente por los grandes grupos (Random House y Planeta, entre otros), entre los cuales resultan particularmente significativos aquellos que abordaron temas vinculados a la coyuntura sociopolítica, en relación con sucesos puntuales o procesos más amplios (Blanc, 2013). Estos libros son difundidos en librerías, ferias y presentaciones de libros, tienen fuerte presencia en los medios y en las redes sociales de las editoriales, de los medios, de los autores y de internautas que replican, intervienen y potencian la circulación de los discursos políticos.

Para adentrarse en la lógica de circulación de los discursos políticos a partir de los libros es importante comprender el proceso por el cual la industria editorial pone a disposición un producto bajo ciertas dinámicas y estrategias. La publicación y difusión de libros es posibilitada por una "ingeniería editorial" que comprende todas las etapas de producción, desde el surgimiento de la idea hasta la comercialización y difusión del libro, pasando por la contratación y construcción del autor, el armado del texto, el diseño de la portada, las estrategias de publicidad y la campaña de prensa y redes sociales. Las editoriales invierten una gran cantidad de recursos para que cada libro sea editado en unos pocos meses y sea redituable para la coyuntura para la que fue lanzado. Por eso, el trabajo de los editores requiere de trabajar con plazos cortos y demostrar capacidad en el trabajo con tendencias que puedan tornarse temáticas atractivas para un libro de consumo masivo. 
Estaba seguro hace tres años que con el kirchnerismo los libros de derecha se iban a vender muy bien, cosa que ocurrió, con Yofre, con Reato. Porque había visto los noventa, que los libros anti menemistas se vendían muy bien. Había descubierto que a la gente le gusta identificarse con los libros que lee (Director Editorial, PRH, comunicación personal, 16 de marzo, 2011).

El objetivo de los editores es que sus libros coincidan con una demanda latente, combinación que no puede ser reducida a un cálculo "científico", sino que es parte de una cotidianeidad práctica (Miguel y Saferstein, 2016). La reconfiguración del mercado editorial implicó nuevas lógicas de edición y nuevos perfiles editoriales, al compás del tratamiento del objeto libro como bien de consumo (Szpilbarg, 2015). Familiarizados con el trabajo y uso cotidiano de distintas plataformas mediáticas que exceden al medio editorial (radio, televisión, prensa y redes sociales) los editores nutren al espacio editorial local de lenguajes y herramientas en sintonía con una lógica transnacional.

Estoy buscando autores nuevos, pensando colecciones, participando en cuestiones que tienen que ver con ventas. Mucho con marketing y comunicación, porque vengo del periodismo. Las redes me ayudan mucho (...) yo trabajo mucho cuando estoy mirando, estás atento a quién se vincula con quién, qué está haciendo, dónde está trabajando (Editora, Siglo XXI, comunicación personal, 5 de agosto, 2018).

Por otro lado, el autor emerge como una figura asociada a una obra mediante la cual interviene en debates políticos o de actualidad que tienen una llegada para amplios públicos. En general los autores tienen una fuerte presencia mediática, cuestión que refleja su centralidad en el debate público. En este sentido, para el sistema editorial y el mediático, estos agentes se construyen y son construidos como "autores marca", con una posición reconocida por el gran público y el mercado, así como también, en varias ocasiones, por otras instancias de consagración como la academia y el ámbito intelectual. Una fracción relevante entre los libros y autores de este segmento editorial es la de los propios políticos. Sea como recurso para presentar su plataforma en campañas electorales, o incluso como un medio para intervenir políticamente más allá de las aspiraciones electorales puntuales, los libros resultan un medio elegido por los agentes vinculados a la política para potenciar su visibilidad.

El sector editorial y sus agentes se conjugan con los medios masivos tradicionales como la televisión, la prensa y la radio, así como con las redes sociales como Facebook, Instagram y Twitter, pero también en espacios públicos y políticos, como las performances de las presentaciones y la participación de los autores y otros intermediarios en distintos eventos. La constante presencia de este fenómeno editorial por distintas vías torna a la producción de libros como un modo de intervención pública y, a las editoriales, como "fábricas" de cultura y de política.

Históricamente el sector editorial se constituyó como una industria cultural con ciclos de producción prolongados. Al estar integrado en general por agentes que participan en espacios de culturalmente más "prestigiados" que los que ocupan quienes se restringen 
a los medios de comunicación tradicionales, los bienes que produce el sector tienen un potencial que puede generar efectos productivos sobre la trama social. Para Robert Darnton (1993), el "efecto libro" se produce gracias a la combinación de distintos procesos que atañen a ese bien cultural. En contraposición a la noticia en la prensa, el libro puede perdurar en el tiempo y articular mensajes y discursos bajo la idea de una totalidad, de "obra". Además, en comparación con otros soportes, el público que accede a los libros es menor al que consume medios masivos. Según Dartnon (1993), estos factores hacen que el libro y sus autores ocupen posiciones social y culturalmente más legítimas que las que pueden ocupar quienes se restringen a medios con ciclos de producción más veloces y menos estables.

La participación de los autores de libros en distintos espacios que no se restringen al editorial (al periodismo y la prensa y los medios en general, a las redes sociales, a la política) lleva a sostener que los escritores de libros adquieren mayor renombre y legitimidad en sus distintos espacios de acción en tanto autores. Es decir que el libro opera con legitimidad y valoración inmerso en un espacio amplio y heterogéneo de soportes y lenguajes de distinto tipo, no como simple accesorio, sino como artefacto cultural valorizado y apoyado en una creencia colectiva construida históricamente.

\section{Las discursividades políticas en las redes sociales}

El libro, la prensa gráfica, la radio, la televisión, así como los medios digitales, constituyen el espacio de la política contemporánea. La generación de discursos políticos en las redes sociales y sus repercusiones en los medios masivos ha producido un "ensanchamiento del espacio público". "Se puso de manifiesto que el público replicante en Internet no solo está constituido por militantes o pertenecientes a partidos políticos, sino que también se ha ensanchado" (Slimovich, 2016, 91). Las democracias contemporáneas se caracterizan por nuevos modos del discurso político: movilizaciones ciudadanas articuladas en el espacio público de internet y un proceso de expansión de los actores, que incluye, ciudadanos comunes, y, entre otros, trolls y bots.

En la era de los medios masivos, en esa primera etapa que Verón (2001 [1984]) denomina "sociedad mediática", las prácticas políticas se ven influidas por los medios masivos de comunicación que se proponen como "espejos" de un "exterior real" y generan así una estrategia de representación. El proceso de mediatización de lo político sufrió cambios con los medios masivos de comunicación, y en particular, se aceleró en el último cuarto del siglo XX. En la "sociedad mediatizada" posterior, la que cuenta con plena hegemonía de los medios masivos de comunicación, especialmente de la televisión, los medios se asumen como capaces de producir hechos y en ese sentido, las prácticas políticas se estructuran en función de las lógicas de los medios masivos (Verón, 2001 [1984]).

La sociedad contemporánea actual está atravesada por la crisis del broadcast (Carlón y Scolari, 2009; Verón, 2011 [2007]) y por un proceso de interrelación entre dos sistemas mediáticos distintos -el de los nuevos medios y el de los medios masivos "en crisis"-, que generan cambios de escala en la mediatización y nuevos modos de conformación de los colectivos (Carlón, 2015, 2016, 2017). 
Los discursos contemporáneos, que emergen en las redes sociales y que tienen puntos de contacto con la televisión, el libro, la prensa gráfica y la televisión, están constituidos por operaciones que provienen del arte contemporáneo, pasaron por los medios masivos y que actualmente traspasaron a los mensajes de los internautas en las redes sociales (Carlón, 2014). Hay básicamente tres operaciones -la apropiación, la intervención y el montaje-, que aparecen en los mensajes en Twitter, Facebook e Instagram de los políticos, autores, editores, periodistas y también de internautas desconocidos.

Hoy, que la apropiación, la intervención y el montaje han llegado ya gracias a la digitalización y a los nuevos medios a la producción cotidiana de millones de usuarios anónimos, no podemos menos que concluir que el efecto Arte contemporáneo se ha vuelto dominante en el ambiente híbrido, mediático y social en el que vivimos (Carlón, 2014, p. 34).

El discurso político mediatizado -el que emerge en los medios masivos- está en interfaz con el informativo/periodístico. En efecto, cuando los políticos están en la radio, en la televisión, en la prensa gráfica o si son autores de libros impresos, se vinculan con la ciudadanía con los periodistas como mediadores (Verón, 2001 [1984]). Las lógicas que atraviesan los discursos de los políticos en noticieros, programas políticos de opinión, de entretenimiento, etc. provienen de una mixtura entre el campo político y el campo mediático (Slimovich, 2016) construyendo muchas veces acontecimientos político-mediáticos, como la difusión de un acto de lanzamiento de campaña bajo el directo televisivo.

Cuando empezaron a surgir los espacios digitales de los políticos, desintermediados de la figura del periodista y de sus lógicas, surgió la pregunta acerca de si las redes sociales de estos líderes estaban o no atravesadas por las reglas del discurso informativo/periodístico. En efecto, se ha probado que los discursos políticos contemporáneos también están en interrelación con los discursos que provienen del informativo televisivo y con las lógicas de los medios masivos. No obstante, se trata de otro tipo de interfaces político-informativasperiodísticas las que circulan en los discursos políticos de las redes sociales (Slimovich, 2012, 2016). Por un lado, los políticos poseen cuentas personales en las redes sociales, en las que los periodistas no son mediadores. Por otro lado, tienden a apropiarse de contenidos de la televisión informativa y a "emular lógicas" y operaciones de los noticieros, los programas políticos de opinión o la prensa gráfica (Slimovich, 2016). Imitan modos y operaciones que provienen de la mediatización en la televisión, prensa gráfica y radio como, por ejemplo, la utilización de la breve informativa en sus propias publicaciones. Asimismo, tienden a reproducir, presentar y representar discursos audiovisuales no televisivos y televisivos. En este sentido, en las cuentas personales de los políticos en Facebook, Twitter, Instagram, Snapchat, Pinterest, YouTube, la enunciación política se impone a la informativa/periodística (Slimovich, 2018), a diferencia de los medios masivos en los cuales es a la inversa.

Para este trabajo se tomó en cuenta la definición de enunciación mediática de Oscar Steimberg, la cual alude a un "efecto de sentido de los procesos de semiotización por los que en un texto se construye una situación comunicacional, a través de dispositivos que podrán ser o no de carácter lingüístico" (Steimberg, 1993, p. 44). Así, "un discurso cons- 
truye una cierta imagen de aquel que habla (el enunciador), una cierta imagen de aquél a quien se habla (el destinatario) y en consecuencia, un nexo entre estos 'lugares" (Verón, 1985, p. 3). En este trabajo se determinará la estrategia enunciativa de la editorial, la del político-autor y la respuesta de los internautas.

\section{La difusión de libros de "coyuntura política" en las redes sociales y los internautas que interpelan}

Los nuevos medios y sus relaciones con los medios masivos de comunicación han generado nuevos tipos de colectivos que surgen en las redes sociales y que pueden llegar a la televisión, el libro, la radio y la prensa gráfica (Carlón, 2015, 2017). En particular, en este trabajo se abordarán los "colectivos de internautas político-mediáticos" (Slimovich, 2016) que se construyen en las redes sociales y que tienen distintos tipos de relación con los políticos y con sus discursos. En tiempos de campaña electoral, y si se tiene en cuenta la triple destinación veroniana (Verón, 1987b), se ha determinado que en primera instancia, en correlación con la figura de "pro-destinatario" que los internautas pueden constituirse como "internautas seguidores" (Slimovich, 2012), y dentro de estos hay un tipo de internauta "militante" que es el que produce contenidos a favor del candidato en las redes sociales, que pone en su perfil en las redes sociales la imagen del político, que utiliza los hashtags que le propone el partido, etc. Por otro lado, en correlación con la figura del "contra-destinatario", se ha advertido que en las redes sociales hay conjuntos de internautas que se articulan en oposición al político, son los que se posicionan contrarios a sus ideas y partido, son los "internautas opositores". Por último, si producen discursividades políticas en reacción o como comentario a la publicación de un político, pero no expresan una opción electoral pueden denominarse "internautas ciudadanos sin opción electoral" (Slimovich, 2012).

En las cuentas de la editorial Planeta y de los autores de los libros se evaluará que tipos de internautas políticos se interpelan.

\section{Las redes sociales del grupo Planeta}

De capital español, Planeta es el principal grupo de lengua castellana y el séptimo en el mundo en cuanto a sus niveles de facturación (de Diego, 2015). Su política expansiva de adquisición de sellos editoriales, además de medios gráficos y audiovisuales, le permitieron anexar los catálogos de míticas editoriales nacionales y españolas como Emecé, Seix Barral, Tusquets, Ariel y Paidós. Esta última, creada en 1945 y una de las protagonistas del proceso de modernización de las ciencias sociales y humanas en la Argentina, es la que le da nombre al área "cultural" del grupo, con las editoriales académicas, de ensayo y de divulgación Ariel, Crítica, Onirio y Paidós. Por otro lado, el área comercial y literaria del grupo la conforman, además de Planeta, una veintena de editoriales de distintas temáticas y alcances como Minotauro, Emecé, Tusquets y Booket. Esta concentración de sellos le permite al grupo Planeta liderar el sector editorial argentino junto a Random House. 
La estrategia digital del grupo replica solo en parte esta división interna. Tiene un sólo sitio web, "Planeta de libros Argentina", que contiene a todos los sellos de la filial argentina, tanto a los del área comercial como a los del área cultural. De modo paralelo, en Instagram también posee una sola cuenta. Sin embargo, en dos de las redes sociales que se analizan aquí, Twitter y Facebook, se observa una separación "permeable", no excluyente, por área. En cada una de estas redes se aglutina la difusión de las novedades de la parte comercial del conglomerado, por un lado, y de la parte cultural y académica, por el otro. Es decir que, por un lado, tanto en Facebook como en Twitter la cuenta "Planeta de libros Argentina", que difunde los acontecimientos, libros y presentaciones vinculadas a las editoriales comerciales y literarias del grupo; y por el otro, las cuentas "Editorial Paidós Argentina" que difunden los acontecimientos, libros y presentaciones vinculadas a los "sellos culturales" y académicos. No obstante, a diferencia de la estructura del conglomerado mediático, en las redes sociales existen algunas intersecciones entre las dos áreas. Luego de realizado el análisis en su conjunto, se puede inferir que cada fin de mes, la cuenta en Facebook: "Planeta de Libros Argentina" anuncia las novedades del mes siguiente mediante un álbum de fotos que contiene las portadas de cada libro. Allí se incluyen las novedades de todo el grupo, es decir, de ambas áreas. Este tipo de publicación constituye el primer anuncio en internet, en tanto antecede al sitio web.

También, existen casos en Facebook y en Twitter, en los cuales algunos títulos del área cultural aparecen como publicaciones no sólo en la cuenta específica, sino también en "Planeta de Libros Argentina", más allá del listado de novedades. Es el caso de la invitación a la presentación del libro Injusticia (2018), del fiscal Federico Delgado, publicado por Ariel y del anuncio y promoción de Pasión por el resultado, de la canciller del gobierno de Macri, Susana Malcorra (2015-2017), publicado por Paidós.

También se observa que hay una diferencia en la actividad de cada una de las cuentas. "Planeta de Libros Argentina" difunde publicaciones diarias que, en cantidad, son muchas más que las de "Editorial Paidós Argentina". En este punto se evidencia un correlato con la orientación de los sellos del grupo y el modo de difundirlos fuera de las redes, en tanto los sellos que poseen una orientación menos comercial del conglomerado también son menos en proporción. La diferencia en el uso de las cuentas por parte del grupo genera asimismo divergencias en los seguidores. El perfil de Facebook de "Planeta de Libros Argentina" tiene ocho veces más seguidores que "Paidós", mientras que el de Twitter lo quintuplica ${ }^{3}$.

De esta manera, el sello del libro de Felipe Solá, Ariel Argentina, publicita sus novedades a través de las redes del área comercial de Planeta, del área cultural y en la web general del grupo. En el caso de Gabriela Cerruti, quien publicó en la histórica colección de libros de "coyuntura política" de Planeta, Espejo de la Argentina, fue anunciada en la web y en el perfil del área comercial. El título fue una de las apuestas del mes por parte del grupo, lo que se evidencia en su visibilidad. Big Macri. Del cambio al FMI (en adelante, Big Macri), cuenta con 15 publicaciones en la cuenta de Facebook del grupo Planeta y nueve en la de Twitter, entre el 9 de agosto y el 21 de septiembre. 


\section{La estrategia enunciativa del Grupo Planeta en las redes sociales}

\section{La difusión de Big Macri. Del cambio al FMI}

En el caso de la obra de Gabriela Cerruti, el Grupo Planeta publica en el sitio web la salida del libro el 1 de agosto de 2018. En Facebook lo hace unos días antes, el 28 de julio; y en Twitter empieza a difundirlo el 21. El instagram de la editorial, si bien tiene publicaciones que refieren a la promoción de libros nuevos en ese mismo período, como Gorda Vanidosa de Lux Moreno, editada por Ariel y difundida el 9 de agosto; o Comer es un placer saludable de Daniela Lopilato el 22, no posee ninguna información del libro Big Macri, evidenciando una estrategia de difusión diferente en las redes de Twitter y Facebook que en Instagram por parte de la editorial.

Tanto en Facebook como en Twitter la editorial alterna dos tipos de publicaciones en relación al libro de Cerruti. Por un lado, una que contiene motivos temáticos (Segre, 1994) vinculados a la presentación del libro: día y hora del evento, oradores, asistentes, etc. Así, se evidencia una "enunciación institucional": se trata de la editorial interpelando a sus internautas-lectores a asistir al evento e informándoles sobre la presentación y la existencia del libro (Imagen 1). Por otro lado, hay mensajes que citan fragmentos de la obra. Las frases escogidas son aquellas que sintetizan la posición de la autora. En este punto, se evidencia otra estrategia enunciativa: se impone la voz política por sobre la institucional (Imagen 2). El modo de producir discursos en las redes sociales en esta modalidad se acerca al modo que adoptan los candidatos en períodos electorales en sus propias cuentas en las redes sociales: es una "enunciación política" (Slimovich, 2016).

Si se retoma la clasificación de los sujetos políticos en las redes que se han mencionado con anterioridad, se puede concluir que en el segundo caso se interpela a dos colectivos político-mediáticos: por un lado, al de "internautas opositores" al macrismo y por otro, al de "internautas seguidores al kirchnerismo". En este punto la editorial se dirige a través de sus espacios en las redes a sujetos políticos. Por el contrario, en el caso de los mensajes que apuntan temáticamente a la difusión de la presentación del libro se dirige a los internautas-lectores. Este tipo de interpelación es la que se detecta en el Instagram del grupo, mientras que en Facebook y en Twitter se alternan las dos estrategias enunciativas. 


\section{Imagen 1}
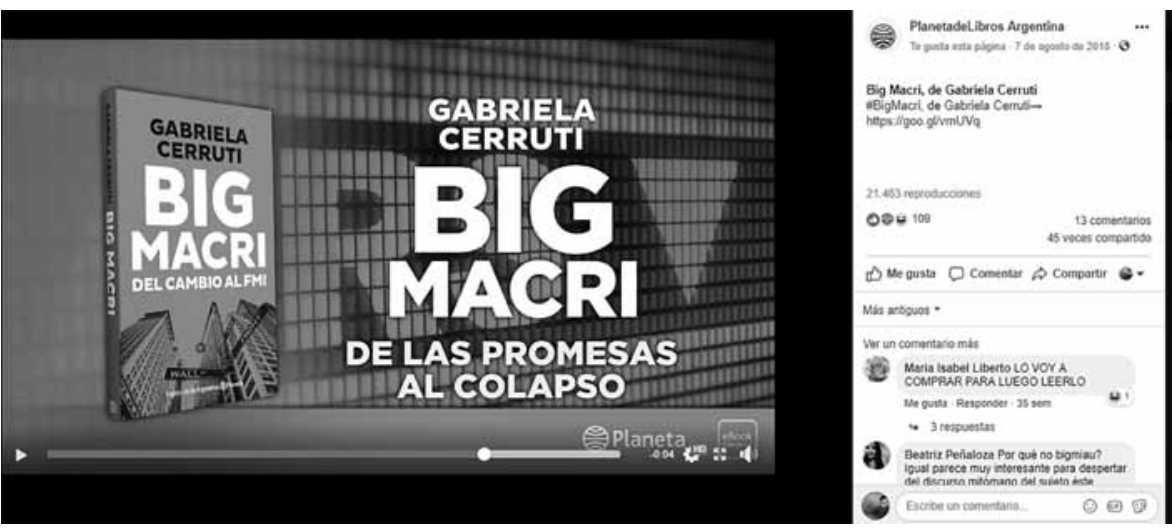

Fuente: Facebook. PlanetadeLibros Argentina, 2018a

\section{Imagen 2}

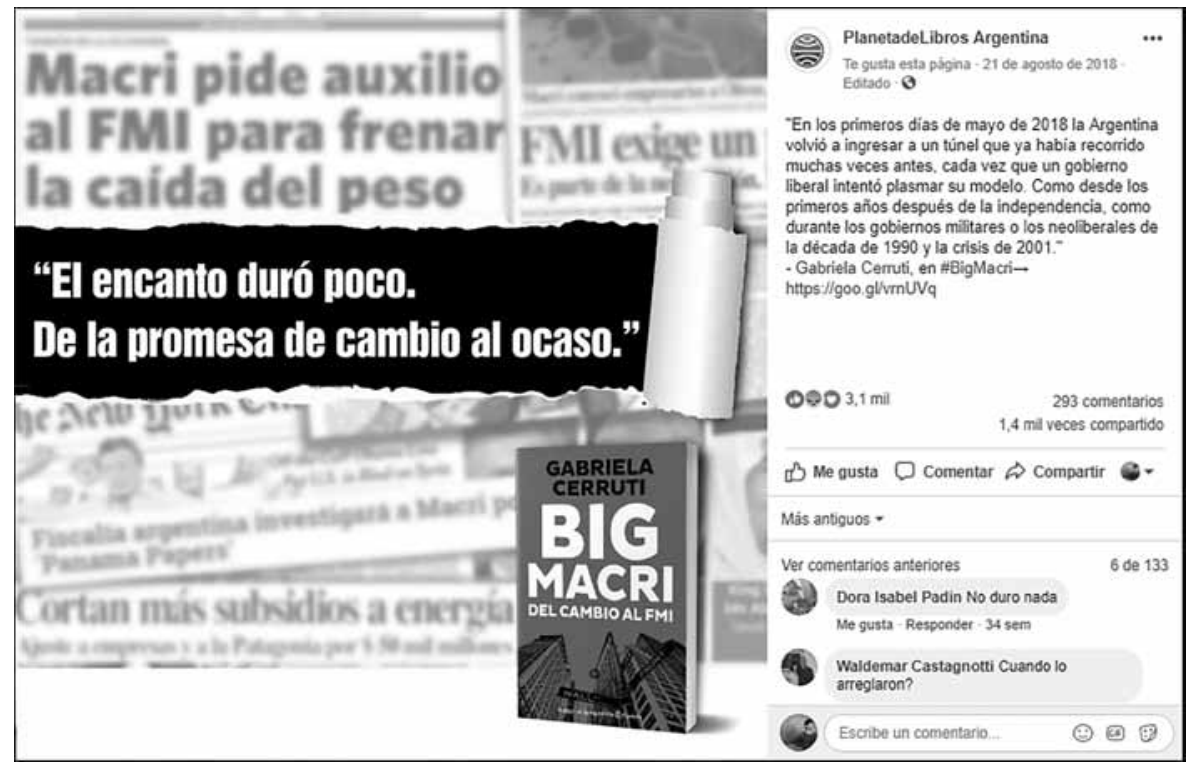

Fuente: Facebook. PlanetadeLibros Argentina, 2018b. 


\section{Las redes sociales de Gabriela Cerruti}

En su vida como periodista y como política, Gabriela Cerruti publicó seis libros, cinco de los cuales son investigaciones periodísticas sobre el poder político: Sus primeros libros, $E l$ octavo círculo (en coautoría con Sergio Ciangalini, 1991, Planeta) y El Jefe (1995, Planeta) fueron investigaciones sobre el menemismo, de los cuales el último fue un gran éxito editorial, con 300.000 ejemplares vendidos. El tercero fue Herederos del Silencio (1997, Planeta), en el que aborda su trayectoria personal y su argumentación en torno al pasado reciente y la dictadura militar. El cuarto libro fue El Pibe (2010, Planeta), el primero que realizó sobre Macri. En 2014 publicó Vivir bien en la ciudad (2014, Aguilar), que no resultó exitoso en términos de ventas. El libro resume sus propuestas para la ciudad de Buenos Aires, territorio por el que compitió como precandidata a Jefa de Gobierno en 2015, aunque sin resultar elegida en las Primarias.

El modo de difusión de Big Macri, su segundo libro sobre Macri, en sus propias redes sociales, es diferente al que realiza el Grupo Editorial; y asimismo también se registran divergencias entre sus cuentas en Twitter, Facebook e Instagram.

Con respecto a Twitter, de modo paralelo a los modos de enunciación política en las redes sociales de períodos anteriores (Slimovich, 2012, 2016, 2017, 2018), en la cuenta de Twitter de la autora se reponen fragmentos televisivos y radiales de las entrevistas que le realizan, en relación a la salida de su libro, generando "discursos argumentativos multimediáticos" (Slimovich, 2012). En efecto, hay una "interfaz digital político-periodística" dado que se replican motivos temáticos (Segre, 1994) vinculados al libro y al momento político de la Argentina. También se citan frases entrecomilladas de sus propias intervenciones en la entrevista y se las vincula con el libro y con la coyuntura (Imagen 3). A diferencia de las publicaciones de la editorial, Cerruti despliega una asociación temática entre el libro, por un lado, y la explicación sobre el "presente del gobierno macrista", por otro. Se apunta a generar el efecto de que el libro puede explicar el presente del gobierno y del país -incluso de que puede apuntar a darle sentido al futuro-. Se despliegan motivos temáticos vinculados a la vida personal de Macri, como la relación con su padre y sus efectos en las decisiones que toma para el país.

En Facebook no se evidencian publicaciones que retomen contenidos de la radio, la televisión ni la prensa gráfica; sino que emergen discursividades que contienen operaciones de apropiación y de intervención de las propias hojas del libro; así como se promociona la presentación del libro en Buenos Aires y en Rosario. No obstante, la estrategia enunciativa es la misma que en Twitter: apunta a mostrar que el libro explica la coyuntura política en el presente (Imagen 4).

En Instagram la estrategia enunciativa de Cerruti está enfocada en constituirse como autora y esto predomina por sobre la construcción de ella como una mujer de la política. Se impone el motivo temático ligado a su rol como escritora de libros que describen el macrismo. Se hace alusión a Big Macri. Del cambio al FMI en serie con su primer libro sobre el presidente argentino: El pibe. En un plano paralelo, se comparten fotos de las estanterías de la librería exhibiendo su obra. Por último, del mismo modo que en Facebook y en Twitter, en su cuenta de Instagram también se registra la operación de apropiarse de frases de su propio libro "para resignificar el presente macrista". 


\title{
Imagen 3
}

\section{Gabriela Cerruti}

@gabicerru

\begin{abstract}
AHORA con @rcaballeroam en @RadioDelPlata | \#BigMacri: "Macri cree que el problema somos nosotros. Que los argentinos no queremos pagar la luz, pagar el gas, que nosotros queremos que el Estado nos resuelva todo":
\end{abstract}

$7: 27$ - 6 ago. 2018

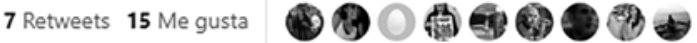

Q 4 切 $7 \quad$ O $15 \quad$

Fuente: Twitter. Gabriela Cerruti, 2018a.

\section{Imagen 4}

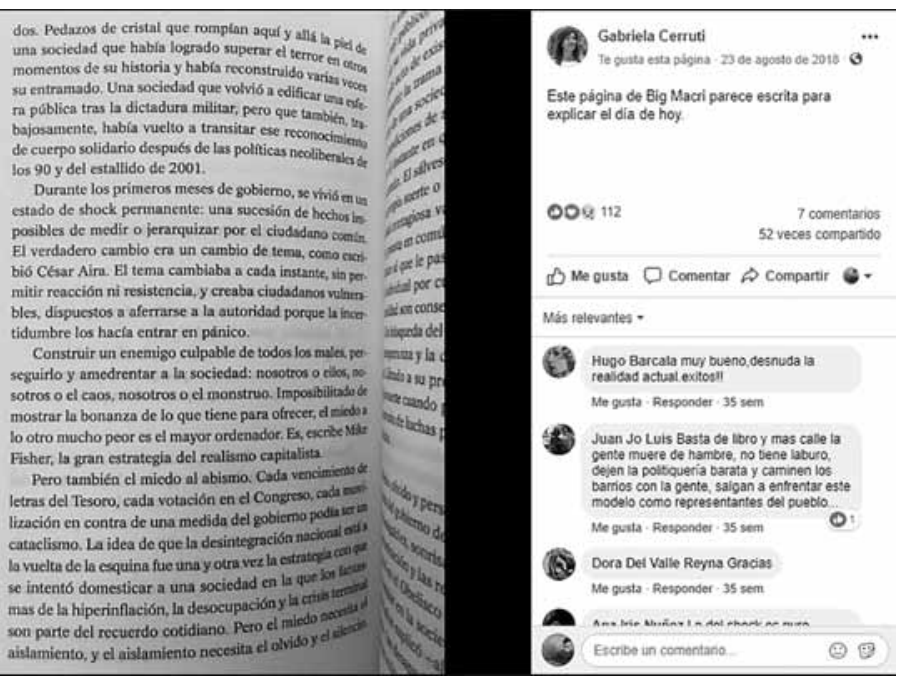

Fuente: Facebook. Gabriela Cerruti, 2018b 


\section{La respuesta de los internautas a Big Macri}

En la primera publicación que "da origen" (Carlón, 2015) a la difusión del libro en Facebook, por parte del conglomerado editorial, el 9 de agosto, se registra información sobre la salida de la obra y su autora a través de un book trailer que se repite en las redes de Cerruti y en las publicaciones en Twitter de la editorial. El book trailer, video promocional que anuncia la novedad, da cuenta del título del libro y del nombre de su autora.

En este punto la respuesta de los internautas responde a dos lógicas. Por un lado, un grupo de comentaristas lo hace en línea con la estrategia enunciativa de la editorial puesto que los mensajes, así como los compartidos, reponen motivos temáticos vinculados a la autoría de la obra, a los soportes que posee el texto, a las cuentas del grupo editorial, y a las expectativas de leer el documento (Imagen 5). Así, se articulan como "internautaslectores" del grupo editorial.

\section{Imagen 5}

Ver un comentario más

Maria Isabel Liberto LO VOY A
COMPRAR PARA LUEGO LEERLO

Me gusta - Responder - 35 sem

69. Gustavo Rodrigo Aredes No tenés plata

Me gusta - Responder - 35 sem

불 Cristina Isabell Martell Está para descargarlo en PDF $\Theta$

Me gusta - Responder - 34 sem

Fuente: Facebook. Gabriela Cerruti, 2018b

Por otro lado, otros internautas responden desde las lógicas de la política partidaria y se articulan en colectivos políticos "seguidores" y "opositores" (Slimovich, 2012). En las publicaciones en las cuales la editorial repone la "estrategia enunciativa política” y se apropia de contenidos opositores al macrismo al citar frases del libro de Cerruti, los comentaristas generan "discursos desde la lógica política" (Slimovich, 2012), conformando tres colec- 
tivos: el de "seguidores kirchneristas", el de "opositores kirchneristas" y el de "seguidores macristas" (Imagen 2). Una conclusión a la que se puede llegar en el análisis de los comentarios de los internautas en el Muro del Grupo Planeta en Facebook y en los retuits y respuestas en Twitter es que los internautas que conforman el grupo de adherentes al gobierno de Macri, se aglutinan a su vez como lectores del grupo Editorial Planeta, y es desde ese lugar, que tienden a responder los ataques al macrismo que realiza el colectivo político-mediático de seguidores kirchneristas.

\section{Peronismo, Pampa y Peligro, de Felipe Solá}

La relación de Solá con el mercado de libros es, a diferencia de Cerruti, muy reciente. $P e$ ronismo, Pampa y Peligro (en adelante, $P P y P$ ) es el primer libro de su autoría, al que se le suma el prólogo a ¿Volverá el peronismo? (Capital Intelectual, 2018), una compilación de ensayos de Juan Carlos Torre, María Esperanza Casullo y Julieta Quirós que salió en una colección coordinada por Martín Rodríguez para Capital Intelectual y Le Monde Diplomatique. La participación más sostenida que tuvo en el mundo de la cultura impresa fue en la revista ligada al reformismo peronista Unidos. En la publicación dirigida por Carlos Chacho Álvarez y de la que participaron también Mario Wainfeld, Claudio Lozano y Arturo Armada, entre otros, Solá participó entre los números 5 y 20, momento en que pasó a ser funcionario de Cafiero. En este sentido, las escasas participaciones de Solá en el mundo editorial están asociadas directamente con su carrera militante y política, a diferencia de Cerruti quien construyó su trayectoria en relación con el mundo del libro y el periodismo. El sitio web del grupo anuncia la publicación del libro de Solá el 1 de octubre de 2018. La salida al mercado había sido difundida en la cuenta de Facebook "Planeta de libros Argentina” el 28 de septiembre, junto a las demás novedades del mes. Esta publicación, a diferencia de la amplia difusión que tuvo Big Macri, es la única sobre $P P y P$ que realiza la cuenta que concentra la difusión del área comercial de la editorial.

En cuanto a la página "Editorial Paidós" en Facebook, la "primera materialización discursiva" que da cuenta de la existencia del libro es posterior: se produce recién el 18 de octubre. Luego, hay tres publicaciones que tienen como motivo recurrente (Segre, 1994) las presentaciones oficiales del libro en distintas ciudades del país, único tema que se registra en las publicaciones de "Editorial Paidós" en Twitter y de la cuenta de Instagram de "Planeta de libros Argentina”. La cuenta de Twitter del grupo no realizó ninguna referencia a la existencia de la obra de Solá.

Se evidencia una diferencia en términos cuantitativos en la promoción de los dos libros, así como en la frecuencia de los mensajes: la difusión que realizó el conglomerado editorial de la obra de Solá fue menor a la de Cerruti. Además, en el caso de Big Macri se registra una periodicidad en las publicaciones, a diferencia de $P P y P$, difundida de modo fragmentario.

La cuenta "Planeta de Libros Argentina" anuncia en Facebook la novedad de Solá junto a otros 41 títulos, de ficción y no ficción de todos los sellos del grupo, tanto los del área comercial como cultural. Además del de Solá, ese mes se publican cuatro libros de coyuntura. Uno de ellos escrito por el periodista Jorge Fontevechia, otro dedicado al "pasado 
reciente", sobre Montoneros y otros dos escritos por políticos: el ensayo de Susana Malcorra y La clase peligrosa. Retratos de la Argentina oculta del dirigente social Juan Grabois. De los libros dedicados a la "coyuntura política", sólo el libro de Malcorra fue anunciado más de una vez en la cuenta del grupo en Facebook. Es decir, este tipo de libros fue mucho menos difundido en las cuentas del grupo en Facebook y Twitter que el resto de los géneros de la editorial durante octubre. En efecto, ese mes primaron las publicaciones vinculadas al día de la madre, utilizando el hashtag \#DíaDeLaMadre y \#AutorasDeLaVida, y se promocionaron obras cuyos autores tenían un elevado historial de ventas en títulos anteriores, como la novela de Florencia Etcheves (Errantes) con ocho publicaciones en Facebook.

En lo que respecta a Twitter e Instagram, solamente fueron difundidas las presentaciones realizadas en Rosario y Tucumán, pero no la presentación institucional del libro de Solá en Buenos Aires. Aquellas presentaciones fueron difundidas en las tres redes al mismo tiempo, como estrategia coordinada.

El modo de difusión de la presentación del libro en las tres redes y en las dos cuentas del grupo "Editorial Planeta Argentina" y "Editorial Paidós" fue a través de dos operaciones. Por un lado, el uso de las "etiquetas" que incluían a los presentadores del libro, como el caso del filósofo Darío Sztajnszrajber, autor y best seller del área Paidós. Por otro lado, la utilización de "hashtags" vinculados al título del libro. En definitiva, la estrategia de difusión de Planeta de la obra de Solá en sus redes sociales implicó el uso de herramientas específicamente destinadas a la interacción con los internautas (Mancera Rueda y Pano Alamán, 2013).

\section{Imagen 6}

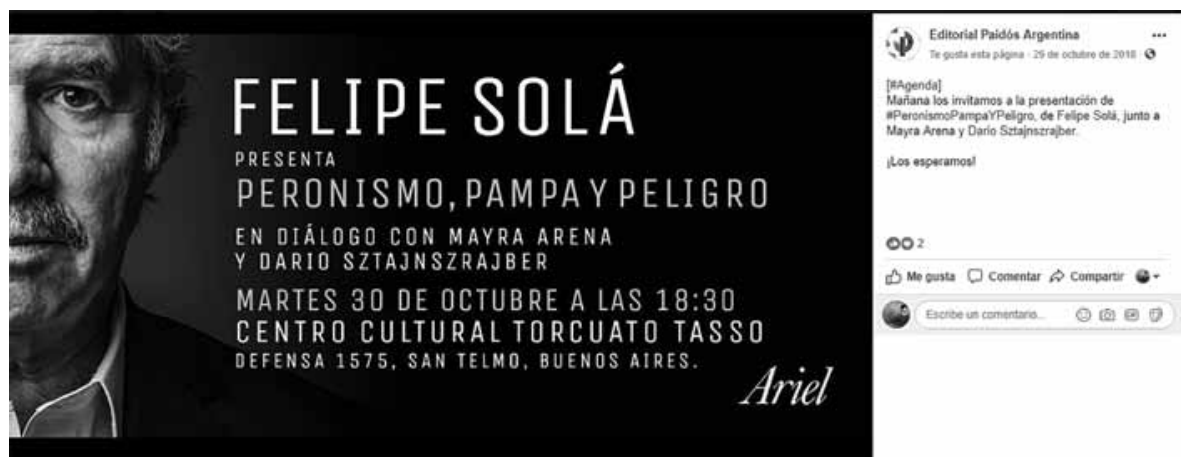

Fuente: Facebook. Editorial Paidós Argentina, 2018

En el caso de Solá la editorial no publicó fragmentos del libro, entrevistas al autor, ni repercusiones de las presentaciones, como sí sucede con otros libros a los que Planeta invierte mayores recursos para su difusión, y como se ha mencionado, sí realizó con el 
libro de Cerruti. Un grupo editorial que publica más de cuarenta novedades mensuales invierte más recursos de publicidad y de marketing digital en las redes sociales (y en otros espacios) para los títulos por los que apuesta como best seller, publicados en los sellos más comerciales (Saferstein, 2016).

En relación con la estrategia enunciativa del grupo Planeta para difundir en sus redes el libro de Sola, se concluye que, a diferencia de la obra de Cerruti, es "institucional e interpela "lectores". La editorial interpela a que los internautas conozcan la salida de un libro y asistan al evento de su presentación (Imagen 6).

\section{$P P y P$ y las redes sociales de Felipe Solá}

Las cuentas personales de Solá en Twitter, Facebook e Instagram movilizaron el libro durante octubre con mucho mayor énfasis que el motorizado por el grupo editorial: 26 publicaciones en la primera, 10 en la segunda y 12 en la tercera. En líneas generales, las redes registran la (auto)construcción de Felipe Solá como autor y como político, en línea con la publicación del mismo durante su campaña por erigirse como candidato presidencial. En esta línea, se registran recorridos por el país con alusiones al libro, entrevistas al autor y comentarios acerca del libro en distintos medios de prensa gráfica, radio y televisión, así como fotos y comentarios de presentaciones realizadas en distintas partes del país (dos en Buenos Aires, en Mendoza, Rosario, Tucumán, entre otras), de las cuales algunas fueron organizadas sin el auspicio explícito de la editorial, sino de organizaciones políticas y unidades básicas. Los contenidos del libro no se presentan de manera explícita como en el caso de Cerruti (quien publicaba fragmentos entrecomillados en sus publicaciones, o mediante imágenes del libro físico), pero sí se hacen alusiones al libro como herramienta para pensar el presente, la coyuntura y la construcción del autor-político como un agente con capacidad para transformarla.

En las tres redes la estrategia que presenta el autor es similar. Las publicaciones sobre el libro, que se concentran en el mes de octubre, se alternan con sus publicaciones sobre sus recorridas proselitistas, reuniones con diferentes actores políticos, académicos o sindicales, así como apariciones en medios de prensa en cuyas publicaciones no se hace alusión exclusiva al libro. Tanto en Twitter como en Facebook se registran reiterados fragmentos mediáticos en donde Solá fue invitado como parte de la campaña de prensa del libro, que no aparece desligada de su construcción como candidato presidencial. En el caso de Instagram sólo se registra una publicación de este tipo, presentada como una foto durante la entrevista que le realizaba María O'Donell para el canal LN+, con la portada del libro de fondo. En el Twitter, Facebook y, en menor medida, en el Instagram de Cerruti se reponen momentos en los que Solá aparece en los medios, generando "discursos argumentativos multimediáticos" (Slimovich, 2012).

La primera publicación de Solá en las tres redes lo presenta como un autor con su obra, a la que define como un relato "sincero" de su vida, con una mirada "personal sobre la política argentina" (Imagen 7). Con esta y las sucesivas publicaciones, al igual que Cerruti, Solá utiliza al libro como herramienta para explicar el presente político. Pero a diferencia de la periodista, el carácter autobiográfico del libro le da un énfasis explícito como objeto 
de memoria política y también de proyecto futuro, en relación con la campaña política personal, potenciada en las redes.

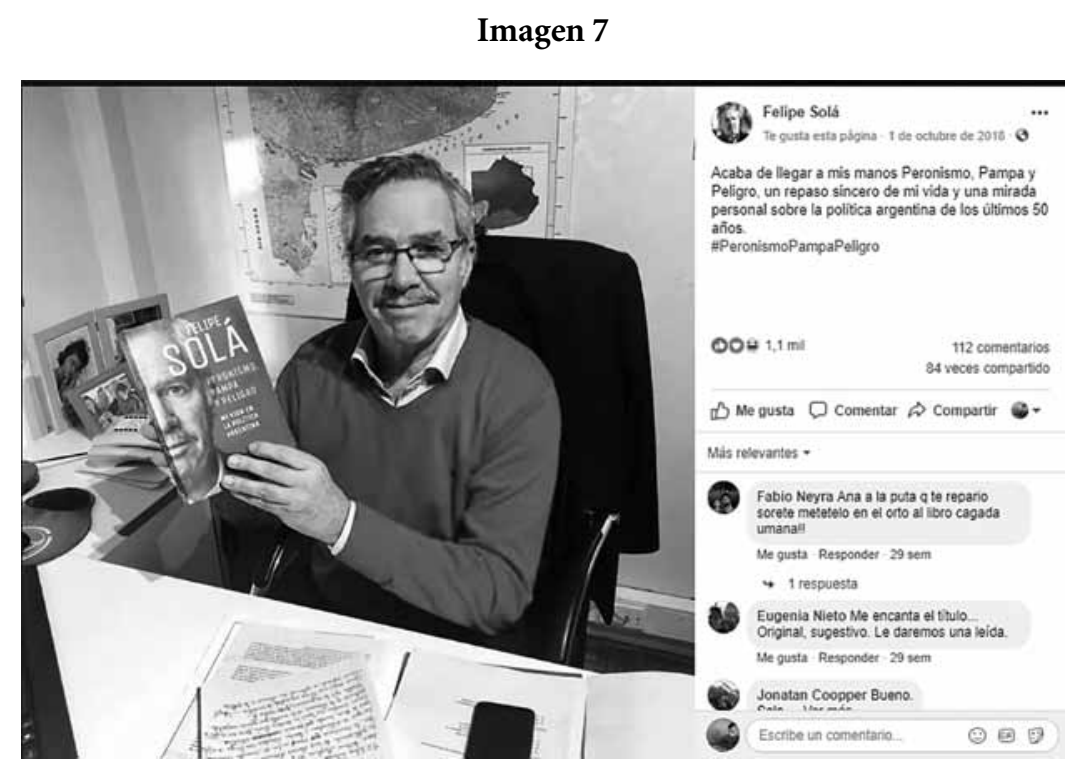

Fuente: Twitter. Felipe Solá, 2018

En esta línea, una dimensión que aparece en la estrategia presentada en las tres redes respecto del libro, es su conformación como un candidato que articula desde la autenticidad con referentes de distintos campos. La idea de "amplitud" se combina con la estrategia enunciativa desde la "honestidad", determinando que emerge tanto en las páginas del libro como en sus cuentas personales en las redes sociales.

Esto se evidencia en el subrayado en las cuentas en Twitter, Facebook e Instagram del político de los comentarios elogiosos de los periodistas, académicos, sindicalistas y demás invitados a la pre-presentación del libro realizada el 2 de octubre, para el área de prensa. Los retuiteos y menciones a los invitados y sus alusiones a su libro son un motivo recurrente de las tres redes sociales. Quienes aparecen rodeando al autor, presentando su libro y elogiándolo, son referentes diversos, reconocidos y no necesariamente afines entre sí dentro del mundo de la política (Alberto Fernández, Fernando Espinoza, Gildo Insfrán, la misma Gabriela Cerruti), el periodismo (Mario Wainfeld, Silvia Mercado, Carolina Ortega, Diego Rojas, Martín Rodriguez y Martín Sivak, quien además es el editor del libro) y la academia (Marcelo Leiras). Esto se ve resumido en un video publicado el 9 de octubre 
en Instagram y Facebook, a propósito de aquella pre-presentación. Allí Solá afirma que el libro fue contratado bajo la condición de que tenía que "decir la verdad".

En resumen, en oposición al tipo de enunciación institucional que realizó el grupo Planeta respecto de $P P y P$, en las redes personales de Solá aparece un tipo de enunciación "política” (Slimovich, 2016). Esta se evidencia en una construcción personal del autor-político, con un mayor énfasis en la segunda parte de este par. Como se ha mencionado, entre las dimensiones que Solá muestra en sus redes (y que aluden al libro publicado) aparecen su experiencia histórica en el movimiento justicialista, en su espacio de interlocutores culturales, intelectuales y políticos autorizados por sectores amplios de la población no reducidos a un "núcleo duro", y, de manera reiterada, el blanqueo y aceptación de sus errores, así como sus aciertos como político. Todos estos factores se contraponen a la enunciación institucional e informativa que aparece desde las redes de la editorial y dan cuenta de la motorización del producto por parte de su autor, un político de carrera con aspiraciones electorales al momento de su publicación.

\section{La respuesta de los internautas a Peronismo, pampa y peligro}

Las respuestas de los internautas a la difusión del libro en las redes del autor presentan divergencias entre las distintas cuentas. En Instagram la primera publicación que da origen a la publicación registra 26 comentarios, todos elogiosos hacia el político y su obra. Por el contrario, en Facebook y Twitter, las lógicas de respuesta están relacionadas a la lógica política, como se describió en el caso de Cerruti. No obstante, se observan matices a la oposición kirchnerismo/antikirchnerismo o peronismo/macrismo, en línea con la estrategia de Solá, quien apuesta a posicionarse por fuera del kirchnerismo.

Por otro lado, y a diferencia de lo que sucedió con Big Macri, las publicaciones sobre $P P y P$ realizadas por las redes de la editorial casi no tuvieron reacciones por parte de los internautas. Las que generaron más interacciones fueron las de Instagram, centradas en difundir presentaciones institucionales del libro. Obtuvieron 119 megusteos y tres comentarios en total. La repercusión en la cuenta de la editorial en Facebook de las publicaciones vinculadas al libro de Solá es muy baja. Entre las dos cuentas del grupo Planeta sólo hay nueve megusteos y ningún comentario. En este sentido, la poca centralidad que le dio la editorial a su producto opacó su visibilidad en sus espacios de difusión y generó baja repercusión digital. Sin embargo, y como se detalla a continuación, el libro tuvo en los medios masivos de comunicación y en las redes sociales, mucha repercusión, dada la visibilidad de su autor, así como por los efectos que se generaron luego de la presentación oficial del libro y la intervención crítica de una de las oradoras.

La presentación en Buenos Aires se realizó el 31 de octubre. Uno de los invitados fue el filósofo Darío Sztajnszrajber, autor y best seller del área Paidós, con una fuerte presencia en el circuito mediático. La otra invitada fue Mayra Arena, quien había cobrado notoriedad y difusión por su presentación “ ¿Qué tienen los pobres en la cabeza? en el evento TedxBahiaBlanca, el 4 de agosto. En el momento en que se realiza la presentación, transmitida vía streaming, la invitada realizó críticas al libro y al propio Solá por su actuación durante el menemismo y por su trayectoria política en general. Los principales medios 
cubrieron ese acontecimiento y resaltaron la crítica de la comentarista al propio Solá, lo que generó reacciones múltiples de los internautas en las redes sociales.

La reacción del político en sus propias redes sociales fue la de darle mayor visibilidad a la crítica recibida y acompañarlo con un descargo. Festejó la sinceridad de Arena y también se vanaglorió de su apertura al invitarla, en línea con la estrategia enunciativa de amplitud y honestidad que sostiene en sus discursos. Sus publicaciones replicaron su autoconstrucción como referente político "articulador" y "dialoguista", que "acepta críticas" para superar la dicotomía entre oficialistas y opositores. En sus propias cuentas, sobre todo en Facebook, la mayoría de las reacciones avalaron la conducta del político, sin criticar a la comentarista. En Twitter, en cambio, predominaron los memes que festejaban la imprevisibilidad del acontecimiento y el descaro de la invitada, así como elogios y ataques al político.

\section{Conclusiones}

Existe una diferencia en la cantidad, frecuencia y estrategia enunciativa de la editorial en la difusión de la obra de Cerruti y la de Solá, publicados, respectivamente, por el sello principal y por un sello "cultural". Esta divergencia se materializa en Facebook, en Twitter y en Instagram, las tres redes analizadas. Se ha mostrado que son muchas más las publicaciones que realiza el grupo Planeta para difundir el libro de Cerruti que el de Solá. Además, la promoción de la obra y de las presentaciones oficiales de $P P y P$ es fragmentaria y esporádica, a diferencia de la de Big Macri, que es más sistemática. La difusión del libro de Cerruti en las redes sociales de la editorial supone una operación de apropiación de contenidos políticos a través de la publicación de fragmentos del manuscrito que colocan a Macri en el lugar del adversario. También se argumentó que este modo de emitir mensajes vinculados al libro de coyuntura política implica un predominio de la "enunciación política" similar a la que realizan los propios políticos argentinos en sus cuentas en las redes sociales en período electoral (Slimovich, 2016). La comparación con el modo de difusión de Planeta del libro de Solá determinó que, por el contrario, este tuvo una "enunciación institucional" de la editorial que interpeló a internautas-lectores, a diferencia de la de Big Macri, que interpeló a "internautas-ciudadanos" (Slimovich, 2012).

Dada la cantidad de libros publicados, las grandes editoriales optan por difundir aquellos que implican una apuesta a convertirse en best seller (Saferstein, 2016). En este sentido cabe preguntarse, ¿Por qué Planeta difunde en las redes sociales ampliamente un libro de coyuntura política realizado por Cerruti, y no le da la misma promoción a la obra de Solá? ¿Por qué el modo de enunciación de la editorial para Big Macri implicó una apropiación e intervención de la posición política antimacrista que posee el libro, cuando en efecto, la propia editorial tiene mayor cantidad de libros escritos por autores cercanos al oficialismo (Saferstein, 2017)? Luego de realizado el análisis, se puede hipotetizar que la apuesta del grupo Planeta en sus redes sociales por la obra de Cerruti es una apuesta a un libro escrito desde el kirchnerismo para explicar el macrismo. En este sentido, se trata de una apuesta a que el best seller puede originarse desde "la grieta". El libro de Solá no interpela del mismo modo la antinomia macrismo-kirchnerismo porque convoca a los "seguidores" y 
"opositores" de Solá. En cambio, el libro de Cerruti interpela a los "internautas seguidores kirchneristas", a los "seguidores macristas", a los "opositores al macrismo" y a los "opositores al kirchnerismo". En este sentido, se puede ver materializado cómo la antinomia macrismo-kirchnerismo que atraviesa la lógica mediática y la lógica política es retomada por el mercado editorial, que le da mayor visibilidad a los productos que la replican y una menor relevancia a los productos que se posicionan más allá de ella.

\section{Notas}

1. El proyecto de investigación titulado "Editores, editoriales y libros de coyuntura política: un acercamiento sociológico a los vínculos contemporáneos entre cultura, economía y política" es llevado adelante por Ezequiel Saferstein y está radicado en el Centro de Documentación e Investigación sobre la Cultura de Izquierdas (CeDInCI/UNSAM) y financiado por el CONICET.

2. El dispositivo analítico de circulación contemporánea se trabaja en "Semiótica de redes", cátedra Mario Carlón, de la Facultad de Ciencias Sociales de la Universidad de Buenos Aires.

3. El 23 de enero de 2019 el perfil de Facebook "Planeta de Libros Argentina" tenía 262.864 seguidores, mientras que el de Twitter tenía 49.100. Por su parte, el perfil "Editorial Paidós Argentina” tenía 32.167 y el de su cuenta de Twitter 9.440.

\section{Referencias bibliográficas}

Carlón, M., y Scolari, C. (eds.) (2009). El fin de los medios masivos. El comienzo de un debate. Buenos Aires: La Crujía.

Carlón, M. (2014). “¿Del arte contemporáneo a una era contemporánea?”. En M.C. Reviglio y F. Rovetto (comps.), CIM. Estado actual de las investigaciones sobre mediatizaciones, $\mathrm{p}$. 24-41. Rosario: UNR Editora. Recuperado: 10/10/2017. Disponible en: http://www.cim. unr.edu.ar/archivos/cuadernodelcim2.pdf

Carlón, M. (2015). "Público, privado e íntimo: el caso Chicas bondi y el conflicto entre derecho a la imagen y libertad de expresión en la circulación contemporánea. En P. César Castro (org.), Dicotomia público/privado: estamos no caminho certo?, p. 211-232. Maceió: EDUFA.

Carlón, M. (2016). “Apropiación contemporánea de la teoría comunicacional de Eliseo Verón”. En E. Vizer y C. Vidales (coords.), Comunicación, campo(s) teorías y problemas. Una perspectiva Internacional, p. 125-153. Barcelona: Editorial Comunicación Social.

Carlón, M. (2017). “La cultura mediática contemporánea: otro motor, otra combustión. (Segunda apropiación de la teoría de la comunicación de Eliseo Verón: la dimensión espacial)". En P. Castro (org.), A circulação discursiva: entre produção e reconhecimento, p. 25-48. Maceió: Edufal.

Carlón, M.; Fraticelli, D.; Slimovich, A. y Rovner, R., (2017). TP.DOC. Documento teórico metodológico. Semiótica de redes. Cátedra Mario Carlón. Buenos Aires: Carrera de Cien- 
cias de la comunicación. Facultad de Ciencias Sociales, UBA. Recuperado: 27/07/2017. Disponible en http://semioticaderedes-carlon.com

Darnton, R. (1993). “«La France, ton café fout le camp !»: De l'histoire du livre à l'histoire de la communication". Actes de la recherche en sciences sociales, 100(1), 16-26. Disponible en https://doi.org/10.3406/arss.1993.3068

de Diego, J. L. (2015). La otra cara de Jano. Una mirada crítica sobre el libro y la edición. Buenos Aires: Ampersand.

Hernández, C., y Saferstein, E. (2018). “El espacio editorial argentino y la construcción de los ferrocarriles metropolitanos como problema público". Question, 1(57), 017. Disponible en https://doi.org/10.24215/16696581e017

Mancera Rueda, A. y Pano Alamán, A. (2013b). El discurso político en Twitter. Análisis de mensajes que "trinan". Barcelona: Anthropos Editorial.

Miguel, P., y Saferstein, E. (2016). Ser una esponja de tendencias: los editores y la "intuición de la demanda" en las grandes editoriales. Astrolabio, 16, 61-92. Disponible en https:// revistas.unc.edu.ar/index.php/astrolabio/article/view/14141

Saferstein, E. (2016). La década publicada. Los best sellers políticos y sus editores: producción de libros, difusión de temas e intervención pública en el mercado editorial argentino (20032015) (Tesis de Doctorado). Universidad de Buenos Aires, Buenos Aires.

Saferstein, E. (2017). La edición como intervención cultural, comercial y política: best-sellers políticos del director de Random House-Sudamericana en el kirchnerismo. Millcayac - Revista Digital de Ciencias Sociales, 4(7), 141-164. Disponible en http://revistas.uncu. edu.ar/ojs/index.php/millca-digital/article/view/1022.

Segre, C. (1985). Principios de análisis del texto literario. Barcelona: Crítica.

Slimovich, A. (2012). "El Facebook de los gobernantes. El caso de Cristina Fernández de Kirchner y de Mauricio Macri”. En M. Carlón y A. Fausto Neto (Comps.), Las políticas de los internautas. Nuevas formas de participación, p. 137-154. Buenos Aires: La Crujía.

Slimovich, A. (2016). La interfaz entre lo político y lo informativo en la mediatización televisiva y las redes sociales en las campañas argentinas de 2009 y 2011 (Tesis de Doctorado). Universidad de Buenos Aires, Buenos Aires.

Slimovich, A. (2017). La ruta digital a la presidencia argentina. Un análisis político e hipermediático de los discursos de Mauricio Macri en las redes sociales. Dixit, 26, 24-43). Recuperado: 04/10/2017. Disponible en: https://revistas.ucu.edu.uy/index.php/revista dixit/article/view/1321/1369

Slimovich, A. (2018). "El macrismo y la oposición kirchnerista en las redes sociales en la campaña electoral de 2017”. Revista Científica Electrónica de la Red de Carreras de Comunicación Social y Periodismo de la Argentina, 6, 6-31. Disponible en http://perio.unlp. edu.ar/ojs/index.php/revcom/article/view/4898

Steimberg, O. (1993). Semiótica de los medios masivos. Buenos Aires: Atuel.

Szpilbarg, D. (2015). Las tramas de la edición mundializada. Transformaciones y horizontes del campo editorial en Argentina 1998-2013 (Tesis de Doctorado). Universidad de Buenos Aires, Buenos Aires.

Verón, E. (1985). “El análisis del 'contrato de lectura'. Un nuevo método para los estudios de posicionamiento de soporte de los media, documento, UBA. (Primera edición: en Les medias: Experiences, recherches actuelles, aplications", IREP, París, 1985). 
Verón, E. (1987a). La semiosis social. Barcelona: Gedisa.

Verón, E.(1987b). La palabra adversativa, Observaciones sobre la enunciación política. En El discurso politico. Lenguajes y acontecimientos. Buenos Aires: Hachette.

Verón, E. (2011 [2007]). La televisión, ese fenómeno "masivo" que conocimos, está condenada a desaparecer. Entrevista a Eliseo Verón. Letra. Imagen. Sonido: Ciudad Mediatizada, 6-7, 31-40. Recuperado: 20/02/2018. Disponible en http://www.revistalis.com.ar/index. $\mathrm{php} /$ lis/article/view/86/85

\section{Fuentes documentales}

Blanc, N. (2013, abril 10). Los libros de un país dividido. ADN. Recuperado de http://www. lanacion.com.ar/1625613-los-libros-de-un-pais-dividido

Cerruti, G. (2018). Big Macri. Del cambio al FMI. Buenos Aires: Planeta.

Cerruti, G. [Gabriela Cerruti]. (6 de agosto de 2018a).Ahora con @caballeroam en @RadiodelPlata \#BigMacri: "Macri cree que el problema somos nosotros... [Tuit] Recuperado de https://twitter.com/gabicerru/status/1026414501275619328

Cerruti, G. [Gabriela Cerruti]. (23 de agosto de 2018b). Esta página de Big Macri parece escrita para explicar el día de hoy. [Actualización Facebook]. Recuperado de https:// www.facebook.com/GabrielaCerruti/

Editorial Paidós Argentina [Editorial Paidós Argentina]. (29 de octubre de 2018). [\#Agenda] Mañana los invitamos a la presentación... [Actualización Facebook]. Recuperado de https://www.facebook.com/EditorialPaidosArg/

Liberto, M. I. [María Isabel Libero]. (9 de agosto de 2018). Lo voy a comprar para luego leerlo. [Actualización Facebook]. Recuperado de https://www.facebook.com/planeta delibrosargentina/

Minutella, E., y Álvarez, M. N. (2017, febrero 22). LAS DESVENTURAS DEL NEWYORKER ARGENTINO. Panamá Revista. Recuperado de http://panamarevista.com/lasdesventuras-del-newyorker-argentino/

Planeta de Libros Argentina [PlanetadeLibros Argentina]. (9 de agosto de 2018a).\#BigMacri, de Gabriela Cerruti [Actualización Facebook]. Recuperado de https://www.facebook. com/planetadelibrosargentina/

Planeta de Libros Argentina [PlanetadeLibros Argentina]. (22 de agosto de 2018b). En los primeros días de mayo de 2018 la Argentina volvió a ingresar a un túnel que ya había recorrido muchas veces antes... [Actualización Facebook]. Recuperado de https://www. facebook.com/planetadelibrosargentina/

Solá, F. (2018). Peronismo, Pampa y peligro. Mi vida en la política argentina. Buenos Aires: Ariel.

Solá, F. [Felipe_Solá]. (1 de octubre de 2018). Acaba de llegar a mis manos Peronismo, Pampa y Peligro, un repaso sincero de mi vida... [Tuit] Recuperado de https://twitter. com/felipe_sola/status/1046872295330000896 


\begin{abstract}
Among the challenges facing university publishers to intervene and compete in a concentrated editorial market, is the assembly of a catalog that concentrates topics and attractive perspectives for a broad audience, as well as the updating of digitization tools for the dissemination of their printed products. Social media -and their logics- became key spaces for the dissemination of books. The work proposes to analyze the emergence and reception of political conjuncture books published in 2018, taking into account the modes of mediatization in social networks, taking as a case the group Planet, one of the main players in the sector.
\end{abstract}

Keywords: Publishers - Books - Social networks - Discourse - Mediatization.

Resumo: Entre os desafios que as editoras universitárias enfrentam para intervener e competir em um mercado editorial concentrado, podemos encontrar a montagem de um catalogo que combina tópicos e perspectivas atraentes para um público amplo, assim como a atualização das ferramentas de digitalização para a difusão de seus produtos impressos. As redes sociais -e suas lógicas- tornaram-se espaços chave para a difusão de livros. O trabalho propõe analisar o surgimento e a recepção dos livros da conjuntura política que foram publicados em 2018, levando em conta os modos da midiatização nas redes sociais, tomando como caso o grupo Planeta, um dos principais atores do sector.

Palavras chave: Editorial - Livros - Redes Sociais - Fala - Midiatização.

[Las traducciones de los abstracts fueron supervisadas por el autor de cada artículo] 